\title{
INTERAÇÕES LOCAIS E TOPOCLIMÁTICAS NO INTERIOR E ÁREAS LIMÍTROFES AO PQ. NACIONAL DA SERRA DO CIPÓ, MINAS GERAIS
}

\author{
Carlos Henrique Jardim ${ }^{\text {(a) }}$ \\ (a) Docente, Depto. Geografia, IGC/UFMG, dxhenrique@gmail.com
}

\author{
Eixo: Climatologia em Diferentes Níveis Escalares: Mudanças e Variabilidades
}

\begin{abstract}
Resumo
Este artigo discute as interações entre fatores climáticos de diferentes escalas espaciais e sua importância como indicador de alterações ambientais e subsídio à definição de unidades climáticas. A área de estudo abrange os limites e interior ao Pq. Nacional da Serra do Cipó em trecho do alto vale do rio Cipó (baixo vale dos rio Mascates e córrego da Serra). A análise apoiou-se em dados oriundos de estações meterológicas (Diamantina, Conceição do Mato Dentro, Sete Lagoas e Belo Horizonte) e produzidos em campo, cujos resultados relacionaram as características de vegetação, topografia e tipos de tempo na organização dos climas e interação entre os diferentes níveis escalares.
\end{abstract}

Palavras chave: vegetação, relevo, clima local, topoclimas.

\section{Introdução}

Os climas se organizam a partir da influência que a superfície exerce sobre a atmosfera, através da interação de fatores como o relevo, vegetação, superfícies oeceânicas etc. com os elementos climáticos (temperatura, umidade do ar, chuvas etc.). Essa acertiva apoia-se no fato de que sendo o ar relativamente permeável a entrada de radiação solar (ondas curtas) ao atingir a superfície essa radiação é absorvida, tendo como resultado o seu aquecimento e, portanto, irradiação de calor (ondas longas) transferida para as camadas sobrejacentes de ar por contato e, de forma mais efetiva, por convecção. Portanto, a fonte de energia do sistema, dada incialmente pela entrada de radição solar, segue trajetória ascendente, a partir da superfície, o que permite situar o núcleo do sistema climático na interface entre os componentes da paisagem e não propriamente na atmosfera.

Essas interações são moduladas pela circulação do ar, bem como pelos fatores de superfície, e se estruturam em diferentes níveis escalares, cuja temática é recorrente numa multiplicidade de trabalhos de cunho geográfico. Bertrand (1972), focando no estudo da paisagem, sustenta a necessidade de inventários detalhados, adoção de uma linha mestra (pode ser a vegetação), testes com diferentes escalas e utilização de cor e trama associada à dinâmica da unidade em relação à situação de equilíbrio (clímax). As escalas definidas variam desde o nível do biótopo, perceptível à escala do terreno, até o nível zonal onde se 
definem os biomas, passando pelos níveis intermediários do geofácie, geossistema, região natural e domínio, cada qual definido pela dimensão e pecularidades em termos de relações. Monteiro $(1975 ; 1999)$ discute as escalas do clima a partir da noção de hierarquia comparável ao esquema de arborescência ou de hierarquia de drenagem, dada pela bifurcação do ramo principal em secundários, terciários e assim por diante, onde cada nível encontra-se embutido em outro, ligado por relações de causa e efeito. Nimer (1989) apresenta proposta aplicada de unidades climáticas para o Brasil, privilegiando o nível regional (regiões norte, nordeste, sudeste, centro-oeste e sul), dento do qual encontra-se o estado de Minas Gerais, relacionando dados obtidos em superfície com a dinâmica das massas de ar.

A noção de escala é insparável da análise climatológica sem a qual é impossível distinguir a dimensão dos fatores ou controles climáticos e impactos decorrentes associados a determinados eventos. Seria como extrapolar a validade de um dado colhido pontualmente para uma área de dimensão do próprio estado de Minas Gerais. Ao considerar a escala, cabe frisar que não se trata propriamente de "escala cartográfica" (relação de proporção entre a realidade e a representação) mas, conforme aponta Castro (1995), de "escala geográfica", ou seja, hierarquia de relações. Isso pode ser compreendido como sinônimo de hierarquia de sistemas, aninhamento hierárquico ou sistemas no interior de sistemas conforme Mattos e Perez Filho (2004). Ribeiro (1993, p.288) distingue níveis hierárquicos superiores e inferiores a partir da relação com fatores diferenciados: "São consideradas escalas superiores àquelas mais próximas ao nível planetário e escalas inferiores aquelas mais próximas dos indivíduos habitantes da superfície da Terra". A definição de "topoclima", categoria escalar explorada neste artigo, ajusta-se àquela definida pelo autor como "variação do clima local devida à rugosidade do terreno, que tem como conseqüência a energização diferenciada do terreno, durante o período diurno, para as diversas faces de exposição à radiação solar” (Idem, p.291). As relações sistêmicas entre o clima e ambiente e os impactos oriundos dessa relação são resgatadas em artigo de Conti (2001) para casos de eventos extremos de chuva e escorregamentos de solo em áreas limótrofes à Serra da Mantiqueira no estado de São Paulo e Minas Gerais.

Jardim $(2007 ; 2010 ; 2015)$ retoma as discussões ao redor dos conceitos de escala e sistemas e aplica à definição de unidades climáticas considerando o clima como objeto temporal e espacialmente dinâmico, ou seja, o desdobramento em diferentes níveis escalares implicaria na integração de fatores, amentando o grau de complexidade em direção às escalas inferiores, já que estariam aí embutidos os efeitos dos fatores que se organizam à escala do objeto e nas escalas superiores ao desse objeto.

A compreensão dessas relações pode ser amplamente aproveitada na definição das unidades de clima através da espacialização de um fenômeno por meio de uma cartografia de síntese, cujo resultado remete a relações com outros componentes do meio, ou seja, no caso do clima, não se trata apenas em considerar o 
produto analítico das mensurações, mas da relação desses atributos com outros atributos do clima e do ambiente (umidade do ar, chuvas, relevo, vegetação etc.) em diferentes níveis de organização e hierarquia. Considerando a discussão anterior, o objetivo deste artigo é apresentar os resultados iniciais da caracterização dos climas locais nas áreas limítrofes ao planalto meridional da Serra do Espinhaço e sua relação com a definição de unidades de menor dimensão espacial, ao nível dos topoclimas, no baixo vale dos rio Mascates e córrego da Serra, no interior do Parque Nacional da Serra do Cipó, visando (1) discutir a importância das variáveis do clima como indicador de alterações ambientais, (2) subsídio à definição de unidades climáticas e (3) contribuir com elementos para a caracterização do clima nessa região do estado de Minas Gerais, parcialmente ausente na literatura científica relacionada à climatologia,

Como se trata de um esboço inicial ainda não foi elaborada proposta de compartimentação espacial das unidades climáticas, apoiada em mapeamento, o que exigirá novos levantamentos em campo (em andamento) e maior detalhamento na análise dos dados produzidos.

A área de estudo (figura 1) situa-se nos espaços limites e interior do Pq. Nacional da Serra do Cipó, tendo

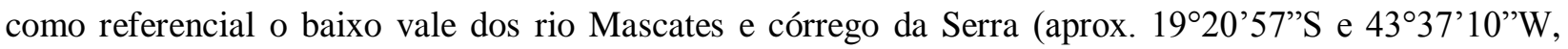
entrada da portaria Areias), em área denominada por Saad (1995) de Planalto Meridional da Serra do Espinhaço, com altitudes variáveis entre 800 - 1600 m, no centro do estado de Minas Gerais, distando em aprox. 72,5 km para nordeste a partir do centro Belo Horizonte e 40,5 km até Conceição do Mato Dentro. A área inclui diversas fitofisionomias de vegetação de cerrado, mata ciliar, vegetação de campos rupestres e mata atlântica. Em relação ao clima, o efeito propiciado pela altitude, no interior de região de clima tropical continental alternadamente seco e úmido, imprime características como a atenuação das variações de temperatura com a elevação do terreno e elevação dos totais de chuvas pelo efeito orográfico. A estação meteorológica do INMET de Conceição do Mato Dentro (DNMET, 1992), dada a sua relativa proximidade em relação à área de estudo, pode ser utilizada como referencial regional do clima, cujos valores de tempertura indicam média de $20,6^{\circ} \mathrm{C}$ e total médio anual de chuva de $1458,7 \mathrm{~mm}$, concentrados de outubro a março, e ventos predominantes do quadrante leste-sudeste, o que indica forte participação da massa tropical Atlântica e sistemas frontais. 


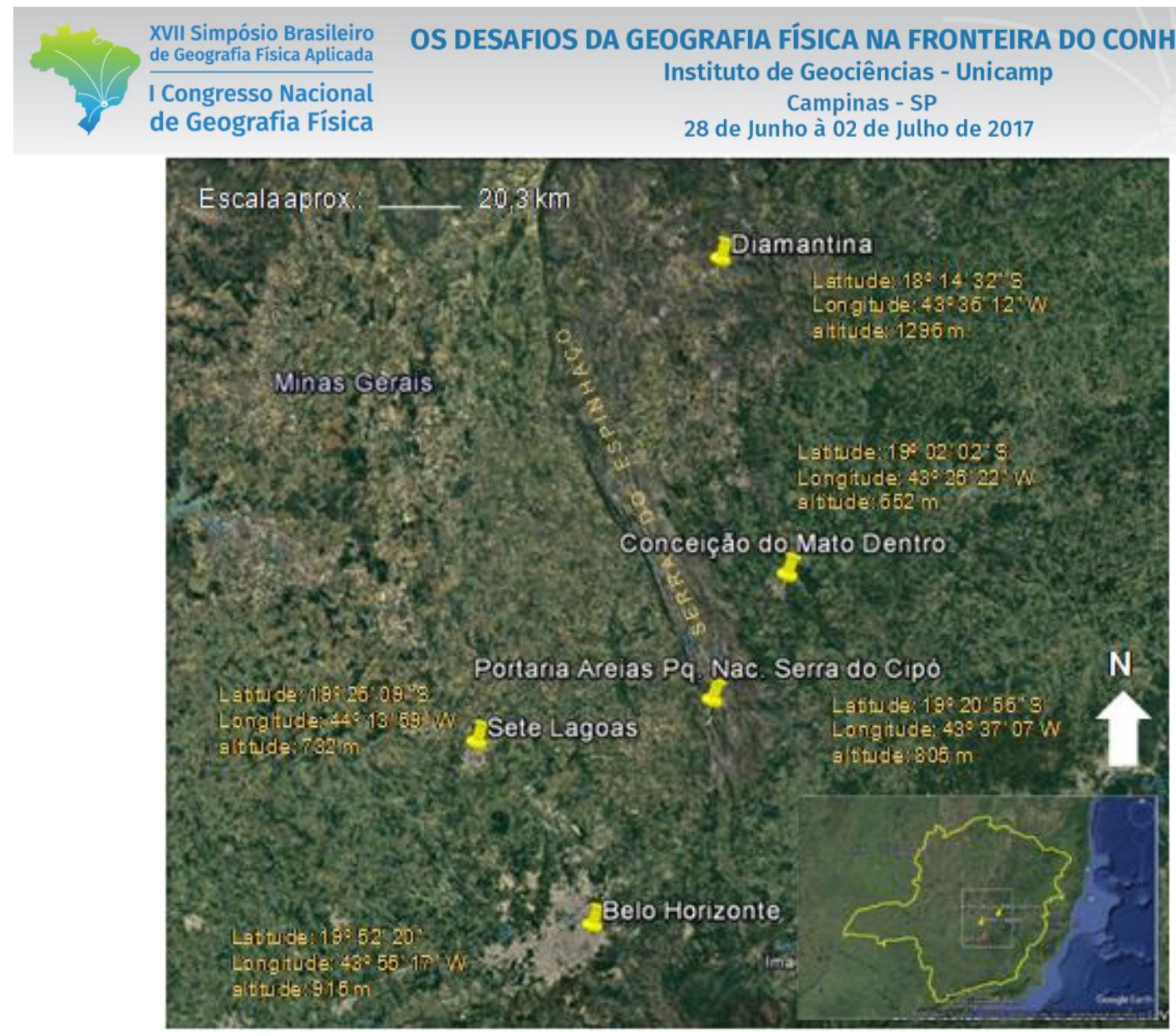

Figura 1 - Localização da área de estudo no estado de Minas Gerais e contexto local. Os valores de latitude e longitude das cidades são aproximados e o valor de altitude corresponde ao das estações meteorológicas do INMET. Destaque para a entrada do Pq. Nacional da Serra do Cipó e a porção sul (borda oeste) da Serra do Espinhaço. Fonte:

Google Earth, fev. 2017.

\section{Materiais e Métodos}

Inicialmente foi realizado o levantamento do material produzido (dissertações, teses, livros, artigos, material cartográfico etc.) e, posteriormente, recuperados dados e discussões de trabalhos elaborados anteriormente, incluindo dados inéditos de coletas em campo ainda não utilizados.

Outra fonte importante de dados referem-se às Normais Climatológicas 1961-1990 (DNMET, 1992), bem como os dados das séries históricas a partir de 1961 das estações meteorológicas oficiais do Instituto Nacional de Meteorologia - INMET (www.inmet.gov.br), por meio de acesso ao seu banco de dados (BDMEP). As estações foram definidas com base em sua proximidade em relação à área de estudo e nas características locais em termos de altitude, relevo e continentalidade/maritimidade e incluíram Diamantina, Conceição do Mato Dentro, Sete Lagoas e Belo Horizonte. Esses dados foram fundamentais para caracterização, numa primeira aproximação, dos espaços climáticos regionais e locais, considerando 
a relação das variações médias dos principais atributos climáticos (temperatura, umidade relativa do ar, chuvas e direção dos ventos) com as características locais de cada uma das estações meteorológicas.

A dinâmica climática em microescala (microclimas e topoclimas) foi caracerizada a partir da análise de dados de temperatura e umidade relativa do ar, apoiada conforme critérios da análise rítmica (MONTEIRO, 1971). Os dados foram produzidos em campo por meio de registradores automáticos (Data Logger - modelo HT 500 e HT 4000) instalados no interior de abrigos meteorológicos, distribuídos em pontos com diferentes características de topografia e de cobertura vegetal. Os períodos de coleta variaram de 02 a 15 dias consecutivos, entre os anos de 2012 e 2016, permitindo avaliar a influência das dieferentes condições de tempo em sucessão contínua. A produção e critérios de análise desses dados foram detalhadas em trabalhos anteriores (MACHADO et al., 2014a; MACHADO et al., 2014b; FIGUEIREDO et al. 2014).

\section{Resultados}

A partir do esboço de uma estrutura hierárquica deve-se considerar, primeiramente, o nível regional, cujos controles básicos referem-se à ação das massas de ar (ou sistemas atmosféricos) em interação com megaestruturas do relevo.

As principais massas de ar que atuam nessa parte do sudeste brasileiro incluem sistemas de alta e baixa pressão atmosférica, de origem tropical e extratropical, associados à ação dos seguintes sistemas: Anticiclone Subtropical do Atlântico Sul (ASAS) - principal sistema atuante durante o ano sobre o estado de Minas Gerais, denunciado pelos ventos predominantes de leste. Embora encerre características de tempo estável, pode ocorrer a formação generalizada de núcleos convectivos pontuais e locais durante o verão, a partir da istabilização do ar em sua base, associado ao aquecimento da superfície e transporte advectivo de umidade do oceano. A permanência desse sistema, sob a forma de bloqueio durante o verão, origina eventos de veranico (período variável sem chuva durante a estação chuvosa) e, no inverno, acelera a perda radiativa de calor a noite, favorecendo contrastes térmicos relativamente acentuados. $\mathrm{O}$ Anticiclone Polar do Atlântico (APA), através da Massa Polar Atlântica (MPA), de origem subpolar, é responsável pelos maiores decréssimos de temperatura a partir da metade do outono e na estação de inverno. No limite desse sistema com o ASAS desenvolve-se a Frente Polar Altlântica (FPA), um dos principais sistemas ligado à produção de chuvas no sul e sudeste brasileiro, ao lado das Linhas de Instabilidade (LI), Zona de Convergência de Umidade (ZCOU) e Zona de Convergência do Atlântico Sul (ZCAS). 
A relação entre as massas de ar descritas com o conjutno de terras altas planálticas do sudeste brasileiro e relativo distanciamento do oceano Atlântico, imprime a área de estudo, na definição de Nimer (1989), características de clima tropical semi-úmido com 4 a 5 meses de seca envolvendo os tipos tropical subquente e tropical mesotérmico brando (este último em áreas de maior valor de altitude, caso da área planáltica da Serra do Espinhaço). O efeito desses fatores está presente nos valores de temperatura (figura 3 - gráfico 1), relativamente moderados quando comparados às regiões norte e nordeste brasileiro ( $\geq 24$ ${ }^{\circ} \mathrm{C}$ ), com valores entre $18,3^{\circ} \mathrm{C}$ em Diamantina e $21,1^{\circ} \mathrm{C}$ em Belo Horizonte, e totais de chuva variando entre com 1271,9 mm em Sete Lagoas e 1463,7 mm em Belo Horizonte (figura 3 - gráfico 8).

O efeito da ação das massas de ar sobre as estruturas de relevo em superfície produzem localmente variações nos atributos climáticos, cujo efeito responde pela estruturação de várias unidades locais de clima. Considerando as características de relevo nas proximidades da área de estudo devem-se levar em consideração duas grandes unidades subregionais definidas por Nimer (1989) embutidas em unidades regionais de clima tropical, a partir das quais foram definidas unidades menores a partir dos dados avaliados: (I) Tropical Subquente Semi-Úmido desdobrada em duas unidades menores: a primeira (A) com caracterísitcas de clima continental a oeste do Espinhaço e a seguda (B) parcialmente exposta aos efeitos oceânicos a leste do Espinhaço. A outra unidade subregional configura-se como (II) Tropical Mesotérmico Brando Semi-Úmido correspondente ao planalto do Espinhaço que se desdobra em unidades menores $(\mathrm{C})$ de topo da área Planáltica da Serra do Espinhaço Meridional. Cada um dos subconjntos (A, B e C) desdobram-se em várias unidades locais que, por sua vez, desdobram-se em mesoclimas e topoclimas (figura 2). A sequência definida apoia-se na proposta de Monteiro (1999) para as escalas do clima.

No interior da unidade IA identifica-se climas locais das áreas drenadas pela bacia do rio São Francisco a oeste do Espinhaço, com climas de características de área continental no reverso da área planáltica do Espinhaço, cuja estação meteorológica representativa é a de Sete Lagoas. Essa situação em meio ao conjunto topografico de sotavento favorece o efeito de compressão do ar, resultante da passagem dos ventos oriundos de leste ao atravessar a Serra do Espinhaço, seguido de aquecimento por compressão adiabática e redução da umidade do ar. A estação de Sete Lagoas, representativa dessa condição (tabela I e figura 2), apresenta o menor valor médio anual de umidade relativa do ar (70,5\% contra $75,7 \%$ de Conceição, 72,2\% de Belo Horizonte e 76,7\% em Diamantina), o menor valor do total de chuva anual (1271,9 mm contra 1458,7 mm de Conceição, 1463,7 mm de Belo Horizonte e 1284,7 mm em Diamantina) e o maior número de horas de insolação (2703,9 contra 2112,8 em Conceição do Mato Dentro). 


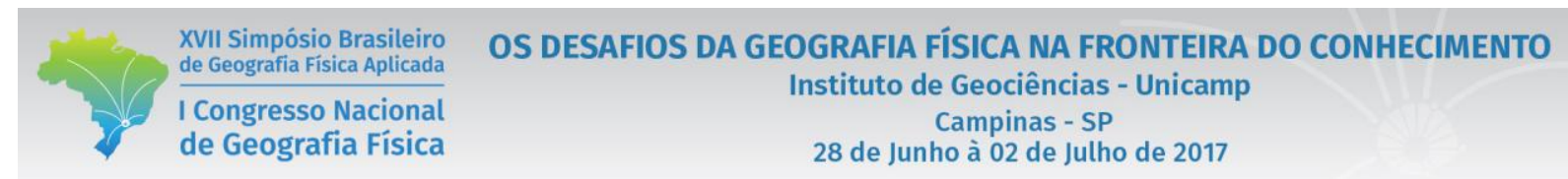

No interior da unidade IB encontram-se as unidades de climas locais do alto vale das bacias que drenam para o Atlântico, a leste da área planáltica do Espinhaço, parcialmente exposta aos efeitos de advecção de umidade oceânica para o interior do continente, com centro na estação meteorológica de Conceição do Mato Dentro. As comparações com as demais estações no parágrafo anterior mostram a msior disponibilidade de água no ambiente.

\begin{tabular}{|c|c|c|c|c|}
\hline Sub-regional & & Local & Mesoclimas & Topoclimas \\
\hline \multirow[t]{2}{*}{$\begin{array}{l}\text { I- Tropical Subquente } \\
\text { Semi-Úmido }\end{array}$} & $\begin{array}{l}\text { A-unidade continental } \\
\text { oeste do Espinhaço }\end{array}$ & $\begin{array}{l}\text { 1,2,3... climas locais das áreas } \\
\text { drenadas pela bacia do rio São } \\
\text { Francisco }\end{array}$ & $\begin{array}{l}\text { Mesoclimas das áreas de (a) topo, } \\
\text { (b) encosta e (c) fundo de vale }\end{array}$ & Topoclimas : i, ii, iii, iv etc. \\
\hline & $\begin{array}{l}\text { B - unidade parcialmente } \\
\text { exposta aos efeitos } \\
\text { oceânicos } \\
\text { leste do Espinhaço }\end{array}$ & $\begin{array}{l}\text { 1,2, } 3 \ldots \text { Climas locais do alto vale } \\
\text { das bacias que drenam para o } \\
\text { oceano Atlântico }\end{array}$ & $?$ & ? \\
\hline $\begin{array}{l}\text { II - Tropical Mesotérmico } \\
\text { Brando Semi-Úmido }\end{array}$ & $\begin{array}{l}\text { C- unidade de topo da } \\
\text { área planáltica da Serra } \\
\text { do Espinhaço Meridional }\end{array}$ & $\begin{array}{l}\text { 1,2,3... climas locais da área } \\
\text { planáltica da Serra do Espinhaço } \\
\text { Meridional }\end{array}$ & $\begin{array}{l}\text { Mesoclimas de topo de vertente: } \\
\text { (a) topo principal; (b) topos } \\
\text { Secundários; }\end{array}$ & Topoclimas : i, ii, iii, iv etc. \\
\hline
\end{tabular}

Figura 2 - Esboço da articulação dos diferentes níveis escalares de clima para a Serra do Espinhaço Meridional e áreas limítrofes. Elaboração: Carlos H. Jardim.

A unidade II corresponde à porção elevada do planalto meridional da Serra do Espinhaço e define-se como um dos conjuntos topográficos de maior altitude do estado, atuando como divisor de águas entre os as bacias do São Fancisco e aquelas que drenam para o oceano Atlântico, estendendo-se longitudinalmente para norte a partir do centro do estado. A altitude impõe-se como um dos principais fatores de controle do clima dessa unidade, atenuando as variações de temperatura e incrementando a ocorrência e totais de chuvas pelo efeito orográfico.

Tabela I - Valores médios anuais dos atributos climáticos $(1961$ - 1990).

\begin{tabular}{|c|c|c|c|c|c|c|c|c|c|}
\hline & \multicolumn{3}{|c|}{ Temperatura $\left({ }^{\circ} \mathrm{C}\right)$} & \multirow{2}{*}{$\begin{array}{l}\text { Insolação } \\
\text { (horas) }\end{array}$} & \multirow{2}{*}{$\begin{array}{l}\text { Evap. } \\
(\mathrm{mm})\end{array}$} & \multirow{2}{*}{$\begin{array}{c}\text { Umid. Relativa } \\
\text { (\%) }\end{array}$} & \multirow{2}{*}{$\begin{array}{l}\text { Precipit. } \\
\text { (mm) }\end{array}$} & \multirow{2}{*}{$\begin{array}{l}\text { Precipit. ? } 1 \text { mm } \\
\text { (num. dias) }\end{array}$} & \multirow{2}{*}{$\begin{array}{l}\text { Direç. Ventos } \\
\text { (graus) }\end{array}$} \\
\hline & média & máxima & mínima & & & & & & \\
\hline Conceição do Mato Dentro & 20,6 & 27,8 & 15,1 & 2112,8 & 836,1 & 75,7 & 1458,7 & 108 & 122 \\
\hline Belo Horizonte & 21,1 & 27,1 & 16,7 & 2569,3 & 1206 & 72,2 & 1463,7 & 93 & 83 \\
\hline Diamantina & 18,3 & $\mathbf{2 3 , 7}$ & 14,1 & 2390,4 & 1297,1 & 76,7 & 1284,7 & 97 & 64 \\
\hline Sete Lagoas & 20,9 & 28,2 & 15,6 & 2703,9 & 1004,9 & 70,5 & 1271,9 & 85 & 85 \\
\hline
\end{tabular}

Fonte: DNMET (1992). 


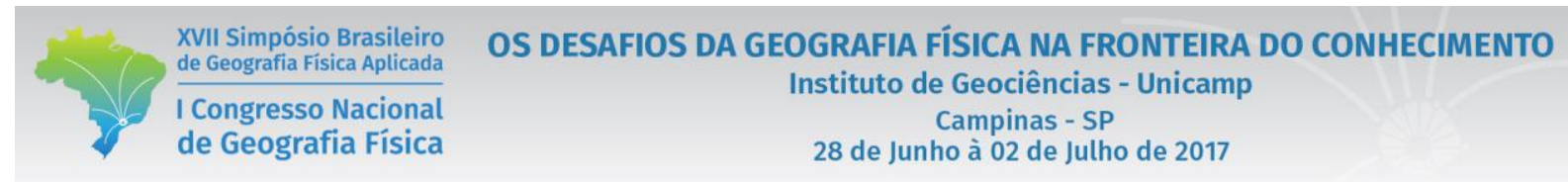

Em função da ausência de estações meteorológicas na área planáltica da Serra do Espinhaço a estação escolhida como representativa dessa condição situa-se no município de Diamantina, centro-norte do estado de Minas Gerais. Embora situe-se a quase $1300 \mathrm{~m}$ de altitude, o que lhe imprime condição de unidade mais fria dentre as estações selecionadas com temperatura média de $18,3^{\circ} \mathrm{C}$ (tabela I), a posição latitudinal mais ao norte das estações utilizadas, confere características de clima que a aproximam da transição para os climas mais secos do norte do estado, com retirada hídrica através do total médio de evaporação pouco superior a entrada de chuva (evaporação de 1297,1 mm contra 1284,7 mm de chuva), o que não se verifica nas outras três localidades.
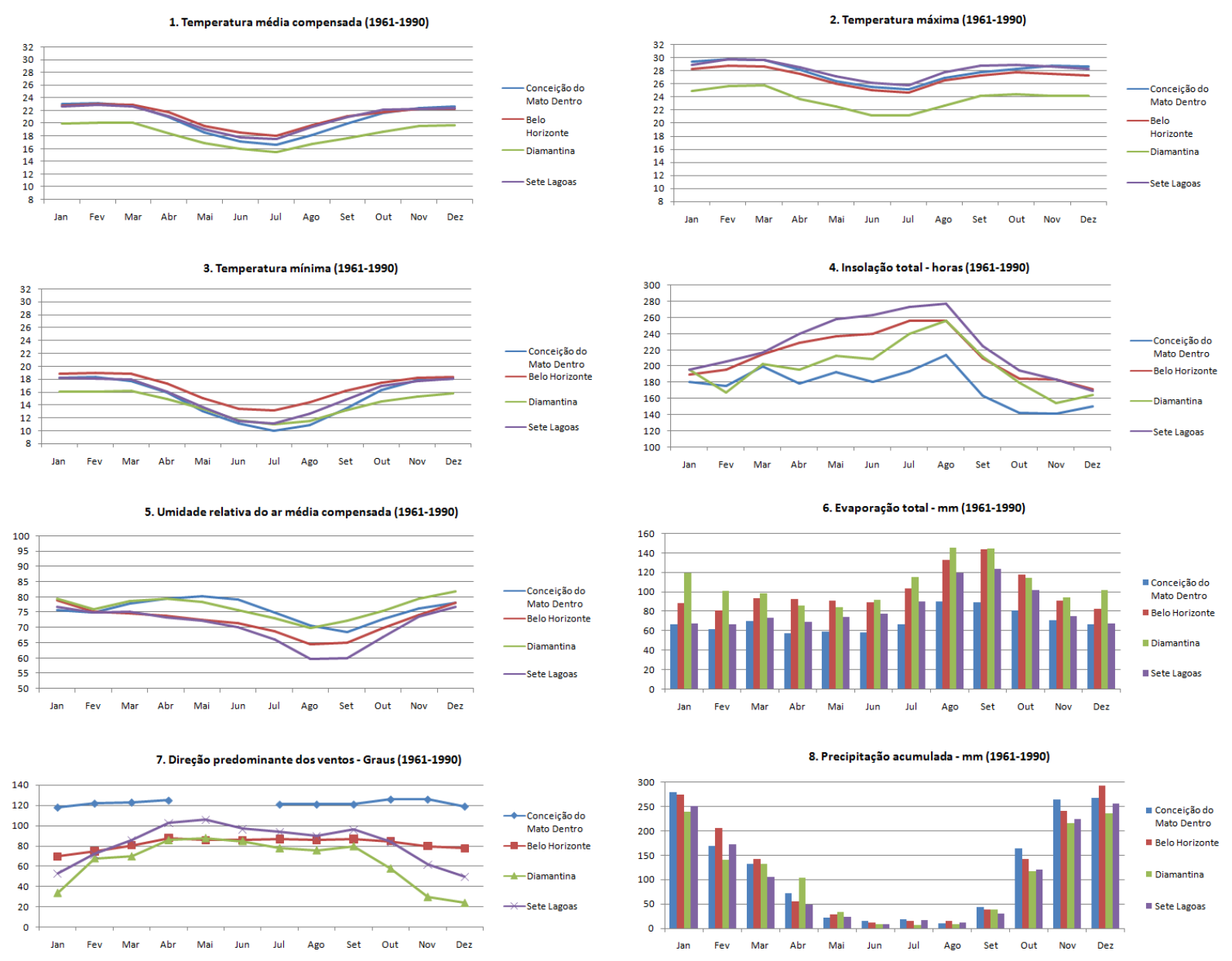

Figura 3 - Variação dos atributos climáticos em Conceição do Mato Dentro, Belo Horizonte, Diamantina e Sete Lagoas. Fonte: Normais Climatológicas 1961-1990 (DNMET, 1992). 
No interior das unidades locais de clima, há um número ainda não definido de unidades de menor dimensão espacial ao nível dos mesoclimas e topoclimas e, certamente, um número incontável ainda maior de unidades microclimáticas.

Os mesoclimas e topoclimas definidos nesta proposta preliminar estão parcialmente embutidos nas unidades locais no interior dos conjuntos A e C (figura 2), abrangendo pelo menos três unidades de mesoclima (topo de vertente, encosta e funda de vale) e quatro unidades topoclimáticas assim distribuídos conforme dados da tabela II: (i) topo de vertente da Serra das Areias (Alto Capão), divisor de águas entre o rios Mascates e o córrego da Serra; (ii) segmento médio da vertente de orientação E-NE da Serra das Areias (postos Mirante e Cerrado Arbóreo); (iii) fundo de vale do rio Mascates e o córrego da Serra (postos da Mata Ciliar e Cerrado); (iv) unidade de transição (entre as unidades ii e iii) entre a base das vertentes das Serras das Areias e o fundo de vale dos rios Mascates e o córrego da Serra.

Tabela II - Valores médios horário-diários dos atributos climáticos (06-09/05 e 10-24/09/2016).

\begin{tabular}{|c|c|c|c|c|c|c|c|c|c|c|}
\hline & \multicolumn{2}{|c|}{ Alto Capāo } & \multicolumn{2}{|c|}{ Cerrado Aberto } & \multicolumn{2}{|c|}{ Cerrado Arbóreo } & \multicolumn{2}{|c|}{ Mata Gliar } & \multicolumn{2}{|c|}{ Mirante } \\
\hline Periodos & Temp. $\left({ }^{\circ} \mathrm{C}\right)$ & UR (\%) & Temp. $\left({ }^{\circ} \mathrm{C}\right)$ & UR (\%) & Temp. $\left({ }^{\circ} \mathrm{C}\right)$ & UR (X) & Temp. $\left({ }^{\circ} \mathrm{C}\right)$ & UR (\%) & Temp. $\left({ }^{\circ} \mathrm{C}\right)$ & UR (\%) \\
\hline $06-08 / 05 / 2016$ & 19,3 & 65,3 & 18,7 & 69,2 & $\mathbf{x}$ & $\mathbf{x}$ & 18,5 & 72,5 & 21,8 & 58,0 \\
\hline $10-24 / 09 / 2016$ & 23,3 & 47 & 24 & 48 & 23,7 & 48 & 23,6 & 49 & $\mathbf{x}$ & $\mathbf{x}$ \\
\hline
\end{tabular}

A unidade de topo (i), representada pelo posto do Alto Capão, é definida pelo próprio contexto altimétrico mais elevado $(986 \mathrm{~m})$ em relação às demais unidades. A vegetação é de cerrado típico e de campo rupestre, com espécies arbóreas de baixo porte em meio à vegetação de porte herbáceo entremeados por afloramentos de rocha, em área de topografia plana. As manchas de solos profundos tipo latossolo ocorrem sob o cerrado. Nas áreas de campo rupestre não há solo ou, quando ocorrem, são pouco profundos e dão suporte para a vegetação típica desse ecossistema como algumas bromélias. A altitude expõe essa área à circulção local e regional, tornando-a menos susceptível aos controles micro e topoclimáticos. Os valores mais baixos de temperatura na seqüência de 10 a 24/09/2016 de 23,3ํ $\mathrm{C}$ (tabela II) são influenciados tanto pela altitude, associado ao efeito de resfriamento decorrente da descompressão adiabática do ar, quanto pela ventilação ligada à circulção local e regional que advecta parte do calor produzido pelas superfícies.

A unidade de encosta (ii), definida pelo segmento médio da vertente de orientação E-NE da Serra das Areias (postos Mirante e Cerrado Arbóreo), abrange áreas de afloramentos de rocha, onde se desenvolvem campos rupestres com vegetação esparsa de pequeno porte. O posto do Mirante é o mais representativo dessa condição. Nessa unidade tem sede processos de circulação de ar influenciado pelo relevo 
XVII Simpósio Brasileiro

de Geografia Fisica Aplicada

I Congresso Nacional

de Geografia Física
OS DESAFIOS DA GEOGRAFIA FÍSICA NA FRONTEIRA DO CONHECIMENTO

Instituto de Geociências - Unicamp

Campinas - SP

28 de Junho à 02 de Julho de 2017

relacionado a movimentos ascendentes e descendentes de ar (ventos anabáticos e catabáticos). Sua orientação N-NE favorece a recepção de radiação solar que, aliada às características de cobertura, transforma-se numa potente fonte de irradiação de calor, coincidindo com os valores mais elevados de temperatura do ar, superior em $2,0^{\circ} \mathrm{C}$ na média quando comparado aos demais postos (tabela II).

A unidade de fundo de vale (iii) inclui áreas de mata ciliar e áreas de cerrado limítrofes a essa formação instalada em terreno de planície e baixos terraços fluviais, com valor de cota altimétrica próximo ao da calha do rio. De acordo com a tabela II essa unidade tende a apresentar os mais baixos valores de temperatura do ar, dividindo essa posição com o posto do Capão. A mata densa obstrui grande parte da entrada de radiação solar, consome a energia disponível no ambiente em seus processos metabólicos, além de disponibilizar água para o ambiente (evapotranspiração), cuja evaporação retira calor latente do ambiente.

A unidade de transição (iv) abrange as áreas de cerrado e cerrado arbóreo situados em terraços fluviais mais antigos e elevados da área de fundo de vale (unidade 3) abrangendo, também, as áreas próximas à base da vertente da Serra das Areias. Os processos que aí se desenvolvem são condicionados pelas demais unidades, principalmente no tocante à influência do relevo, desencadeando moviementos ascendentes e descendentes do ar.

\section{Considerações Finais}

$\mathrm{Na}$ análise climatológica caberia antes de tudo identificar os fatores ou controles responsáveis pela organização de um dado espaço climático. Embora o dado de clima colhido em superfície represente uma integral de todo tipo de relações, não é possivel confundir a influência de objetos da dimensão da cordilheira dos Andes com aquela exercida pela pelo segmento voltado para noroeste da Serra do Curral nas cercanias de Belo Horizonte. Objetos de dimensões distintas influenciam o clima de forma também distitinta. Enquanto a primeira praticamente separa a circulação do ar ao nível dos centros de ação ciclonais e anticiclonais na porção sul dos oceanos Pacífico e Atlântico, a segunda exerce influência topoclimática drenando ar frio do alto da serra para o bairro Mangabeiras em Belo Horizonte.

Diferenças entre seqüências de dados, quando analisados de forma comparativa, muitas vezes devem-se às características locais e não propriamente às características dos fatores diretamente envolvidos na mensuração dos elementos. A ação de fatores que estruturam espaços climáticos de maior dimensão influenciam diretamente na organização de espaços climáticos de menor dimensão. 


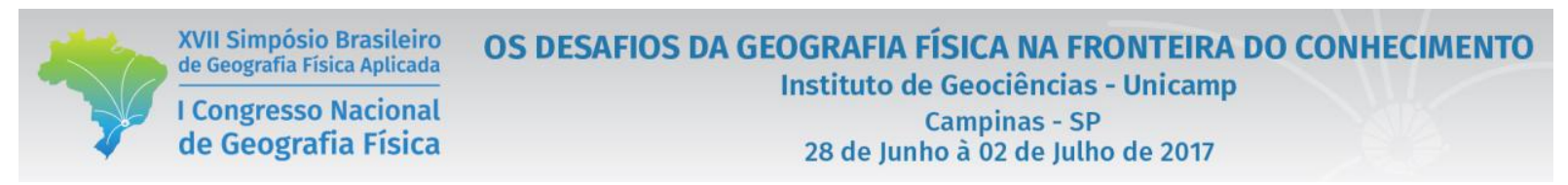

\section{Bibliografia}

BERTRAND, G. Paisagem e geografia física global: esboço metodológico. Caderno de Ciências da Terra, São Paulo, v.13, p.1-27, 1972.

CASTRO, I. E. O problema da escala. In: CASTRO. I. E. et al. (Orgs.) Geografia: conceitos e temas. Rio de Janeiro: Bertrand Brasil, 1995.

CONTI, J. B. Resgatando a "fisiologia da paisagem". Revista do Departamento de Geografia, São Paulo, n.14, p. 59-68, 2001.

DNMET. Departamento Nacional de Meteorologia. Normais Climatológicas (1961- 1990). Brasília-DF, 1992.

FIGUEIREDO, J. M.; MONTEIRO, H. C.; LEAL, L. F. G.; ASSIS, W. L. Identificação e caracterização dos microclimas da porção oeste do Parque Nacional da Serra do Cipó (MG). In: XI Simpósio Brasileiro de Climatologia Geográfica (XI SBCG - IV SPEC - COC UGI MEETING): VARIABILIDADE E MUDANÇAS CLIMÁTICAS: ESTADO DA ARTE E PERSPECTIVAS DA INTERAÇÃO SOCIEDADE-NATUREZA, 2014, Curitiba-PR. Anais... Curitiba: UFPR, 2014. v. 1. p. 1072-1084.

JARDIM, C. H. Proposta de síntese climática a partir do comportamento térmico e higrométrico do ar em áreas urbanas. Tese (Doutorado em Geografia) - Departamento de Geografia - Instituto de Geociências - Universidade Estadual de Campinas, Campinas, 2007.

JARDIM, C. H. A representação gráfica dinâmica como subsídio à elaboração da carta de unidades climáticas. Geografias, Belo Horizonte, n.10, p.140-151, jan./jun. 2010.

JARDIM, C. H. Aspectos Multiescalares e Sistêmicos da Análise Climatológica. Geografias, Belo Horizonte, Edição Especial - III Seminário de Geografia Reflexões sobre o III Seminário de Geografia (III SEGEO), p.40-52, 2015.

MACHADO, F. L. V.; NERY, F. H.; COELHO, J. P. R.; JARDIM, C. H. Aspectos do clima e paisagem em trecho do Parque Nacional da Serra do Cipó-MG: variações horárias de temperatura e umidade relativa do ar no período de 11 a 13/04/2014. In: XI Simpósio Brasileiro de Climatologia Geográfica (XI SBCG - IV SPEC - COC UGI MEETING): VARIABILIDADE E MUDANÇAS CLIMÁTICAS: ESTADO DA ARTE E PERSPECTIVAS DA INTERAÇÃO SOCIEDADE-NATUREZA, 2014, Curitiba-PR. Anais... Curitiba: UFPR, 2014a. v.1. p.272-283.

MACHADO, L. A.; GONCALVES, I.; MAGALHAES, M. A. N.; ASSIS, W. L. Análise do comportamento térmico e hígrico em área do Parque Nacional da Serra do Cipó. In: XI Simpósio Brasileiro de Climatologia Geográfica, 2014, Curitiba. XI Simpósio Brasileiro de Climatologia Geográfica. Anais... Curitiba: UFPR, 2014b. v.1. p.449-460.

MATTOS, S. H. V. L. de; PEREZ FILHO, A. Complexidade e estabilidade em sistemas geomorfológicos: uma introdução ao tema. Revista Brasileira de Geomorfologia, n.1, p.11-18, 2004.

MONTEIRO, C. A. F. Análise rítmica em Climatologia. Problemas da atualidade climática em São Paulo e achegas para um programa de trabalho. São Paulo: Climatologia, n. 1, 1971. p.1-21.

MONTEIRO, C. A. F. Teoria e Cima Urbano. Tese (Livre Docência) - Faculdade de Filosofia, Letras e Ciências Humanas, Universidade de São Paulo, São Paulo, 1975.

MONTEIRO, C. A. F. O estudo geográfico do clima. Cadernos Geográficos, Florianópolis, n.1, 1999.

NIMER, E. Climatologia do Brasil. 2.ed. Rio de Janeiro: IBGE, 1989.

RIBEIRO, A. G. As escalas do clima. Boletim de Geografia Teorética, n.45-46, p.288-294, 1993.

SAAD, A. A geomorfologia da Serra do Espinhaço em Minas Gerais e de suas margens. Geonomos, v.3, n.1, 1995. 